\title{
Correction to: Immunostimulatory RNA leads to functional reprogramming of myeloid-derived suppressor cells in pancreatic cancer
}

Philipp Metzger ${ }^{1 \dagger}$, Sabrina V. Kirchleitner ${ }^{1,2+}$, Michael Kluge ${ }^{3}$, Lars M. Koenig ${ }^{1}$, Christine Hörth ${ }^{1}$, Carlotta A. Rambuscheck', Daniel Böhmer', Julia Ahlfeld ${ }^{1}$, Sebastian Kobold ${ }^{1}$, Caroline C. Friedel', Stefan Endres ${ }^{1}$, Max Schnurr ${ }^{1+}$ and Peter Duewell ${ }^{1,4^{*}+}$

Correction to: J ImmunoTher Cancer (2019) 7:288 https://doi.org/10.1186/s40425-019-0778-7

Following publication of the original article [1], the authors have reported that Fig. 2 and Additional file 1: Figure S1, S2 partially show red scripts.

In Fig. 2:

- A: Red font "MHC-I (MFI x 103)" should change to black font;

- C: Red font "0.07" and "M-MDSC" should change to black font.

In Additional file 1: Figure S1, S2:

- S1: Red font "Spleen" and "Tumor" should change to black font;

- S2: Red font "C", "D", "E", "F", "G", "H" should change to black font.

The correct version of the figures can be found below. The corrections have been implemented in the original article as well.

We apologize for the inconvenience.

\section{Supplementary information}

Supplementary information accompanies this paper at https://doi.org/10. 1186/s40425-019-0830-7.

Additional file 1: Figure S1. Gating strategy for the identification of MDSC populations. Figure S2. Poly(l:C)c reduces macrophage frequency and activates macrophages, CDC, B and NK cells. Figure S3. Poly(l:C)c triggers transcriptional reprogramming of MDSC. Figure S4. Significantly regulated genes in PMN- and M-MDSC upon poly(l:C)c therapy.

\section{Author details}

${ }^{1}$ Center of Integrated Protein Science Munich (CIPSM) and Division of Clinical Pharmacology, Klinikum der Universität München, Lindwurmstrasse 2a, 80337 Munich, Germany. ${ }^{2}$ Department of Neurosurgery, University Hospital, LMU Munich, 81377 Munich, Germany. ${ }^{3}$ Institute for Informatics,

Ludwig-Maximilians-Universität München, 80333 Munich, Germany. ${ }^{4}$ Institute of Innate Immunity, University of Bonn, Venusberg-Campus 1, 53127 Bonn, Germany.

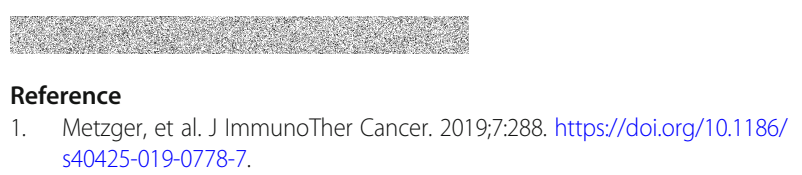

The original article can be found online at https://doi.org/10.1186/s40425 019-0778-7

* Correspondence: pduewell@uni-bonn.de

${ }^{\dagger}$ Philipp Metzger and Sabrina V. Kirchleitner contributed equally to this work. ${ }^{\dagger}$ Max Schnurr and Peter Duewell contributed equally to this work.

${ }^{1}$ Center of Integrated Protein Science Munich (CIPSM) and Division of Clinical Pharmacology, Klinikum der Universität München, Lindwurmstrasse 2a, 80337 Munich, Germany

${ }^{4}$ Institute of Innate Immunity, University of Bonn, Venusberg-Campus 1,

53127 Bonn, Germany

Full list of author information is available at the end of the article 


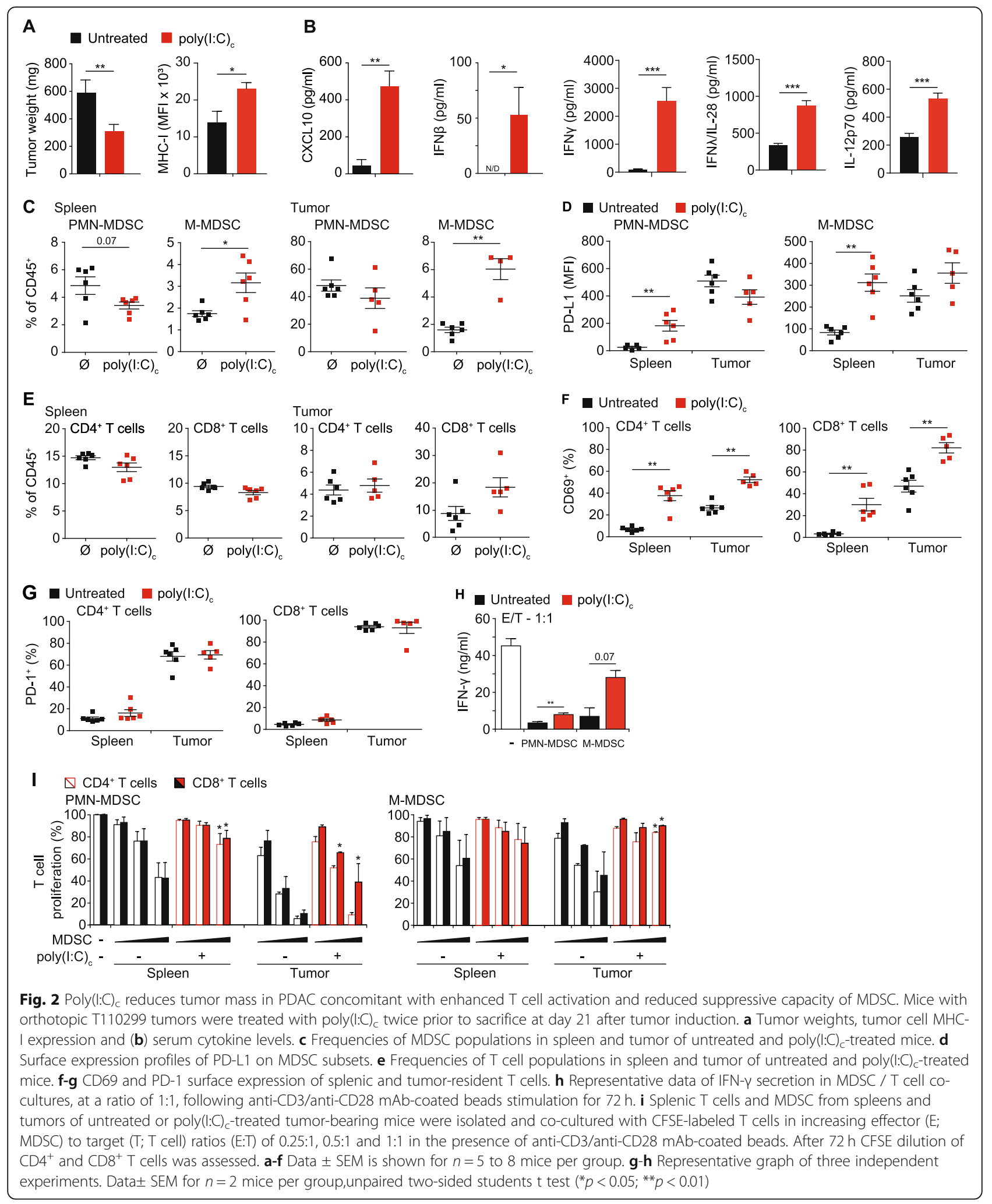




\title{
Immunostimulatory RNA leads to functional reprogramming of myeloid-derived suppressor cells in pancreatic cancer
}

Philipp Metzger ${ }^{1 \dagger}$, Sabrina V. Kirchleitner ${ }^{1,2 \dagger}$, Michael Kluge ${ }^{3}$, Lars M. Koenig ${ }^{1}$, Christine Hörth', Carlotta A. Rambuscheck', Daniel Böhmer', Julia Ahlfeld', Sebastian Kobold', Caroline C. Friedel', Stefan Endres ${ }^{1}$, Max Schnurr ${ }^{1+}$ and Peter Duewell ${ }^{1,4^{*}}$ (D)

\begin{abstract}
Background: The tumor microenvironment (TME) combines features of regulatory cytokines and immune cell populations to evade the recognition by the immune system. Myeloid-derived suppressor cells (MDSC) comprise populations of immature myeloid cells in tumor-bearing hosts with a highly immunosuppressive capacity. We could previously identify RIG-I-like helicases (RLH) as targets for the immunotherapy of pancreatic cancer inducing immunogenic tumor cell death and type I interferons (IFN) as key mediators linking innate with adaptive immunity.

Methods: Mice with orthotopically implanted $\mathrm{Kras}^{\mathrm{G} 12 \mathrm{D}} \mathrm{p} 53^{\mathrm{fl} / \mathrm{R} 172 \mathrm{H}} \mathrm{Ptf1a-Cre} \mathrm{(KPC)} \mathrm{pancreatic} \mathrm{tumors} \mathrm{were} \mathrm{treated}$ intravenously with the RLH ligand polyinosinic-polycytidylic acid (poly(l:C)), and the immune cell environment in tumor and spleen was characterized. A comprehensive analysis of the suppressive capacity as well as the whole transcriptomic profile of isolated MDSC subsets was performed. Antigen presentation capability of MDSC from mice with ovalbumin (OVA)-expressing tumors was investigated in T cell proliferation assays. The role of IFN in MDSC function was investigated in $\mid$ fnar $^{-1-}$ mice.

Results: MDSC were strongly induced in orthotopic KPC-derived pancreatic cancer, and frequencies of MDSC subsets correlated with tumor weight and G-CSF serum levels, whereas other immune cell populations decreased. Administration of the RLH-ligand induced a IFN-driven immune response, with increased activation of T cells and dendritic cells (DC), and a reduced suppressive capacity of both polymorphonuclear (PMN)-MDSC and monocytic (M)-MDSC fractions. Whole transcriptomic analysis confirmed an IFN-driven gene signature of MDSC, a switch from a M2/G2- towards a M1/G1-polarized phenotype, and the induction of genes involved in the antigen presentation machinery. Nevertheless, MDSC failed to present tumor antigen to T cells. Interestingly, we found MDSC with reduced suppressive function in Ifnar1-deficient hosts; however, there was a common flaw in immune cell activation, which was reflected by defective immune cell activation and tumor control.

(Continued on next page)
\end{abstract}

\footnotetext{
* Correspondence: pduewell@uni-bonn.de

${ }^{\dagger}$ Philipp Metzger and Sabrina V. Kirchleitner contributed equally to this work.

${ }^{\dagger}$ Max Schnurr and Peter Duewell contributed equally to this work.

${ }^{1}$ Center of Integrated Protein Science Munich (CIPSM) and Division of Clinical

Pharmacology, Klinikum der Universität München, Lindwurmstrasse 2a, 80337

Munich, Germany

${ }^{4}$ Institute of Innate Immunity, University of Bonn, Venusberg-Campus 1,

53127 Bonn, Germany

Full list of author information is available at the end of the article
} 


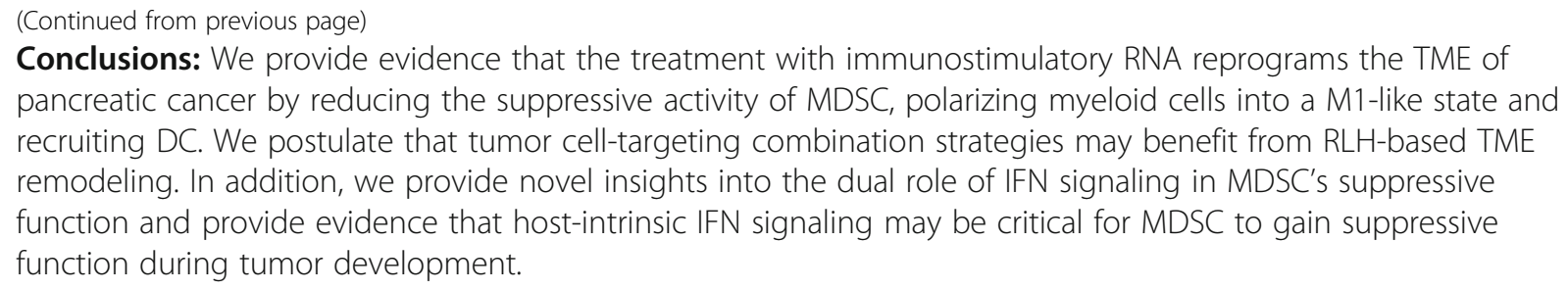

Keywords: MDSC, Type I IFN, Poly(I:C), MDA5, Pancreatic cancer, Immunotherapy

\section{Background}

Pancreatic ductal adenocarcinoma (PDAC) is predicted the second most frequent cause for cancer-associated death in the Western world [1]. However, no immunotherapeutic approach has been approved for PDAC so far [2]. A hallmark of tumors is the immunosuppressive network with the recruitment of immune cell populations that effectively dampen $\mathrm{T}$ cell function and promote tumor growth. Thus, there is a great unmet need towards a better understanding of the suppressive tumor microenvironment (TME) and its role for immunotherapeutic failure.

Chronic low-grade inflammation is a known risk factor for carcinogenesis and is involved in desmoplastic conversions characterized by a high infiltration of non-malignant stromal and immune cells $[3,4]$. The frequency of peripheral blood myeloid cells correlates with the disease stage of PDAC patients [5] and the infiltration of macrophages, neutrophils and regulatory $\mathrm{T}$ cells $\left(\mathrm{T}_{\text {reg }}\right)$ into the tumor serves as a negative prognostic marker for survival [6]. Based on immune cell infiltration, tumors can be classified as "cold" tumors, in which immune cell infiltration - especially $\mathrm{T}$ cells - is sparse; those tumors mostly fail to respond to immunotherapies [7, 8]. On the other hand, "hot" tumors are densely infiltrated with $\mathrm{T}$ cells, which indicates an immunological active TME susceptible for immunotherapy with checkpoint inhibitors. PDAC creates an immune-privileged TME that is characterized by low $\mathrm{T}$ cell frequencies that lack functionality to fight cancer cells due to a negative immune regulation in the TME $[9,10]$. Along this classification, PDAC is a graving example of a "cold" tumor [11].

An interesting approach for turning "cold" tumors "hot" could be reprogramming of the TME into an immunepermissive state. PDAC show high frequencies of Kras mutations with high secretion of growth factors such as granulocyte-macrophage colony-stimulating factor (GMCSF) and granulocyte colony-stimulating factor (G-CSF), which are responsible for emergency myelopoiesis recruiting myeloid cells into the TME [12, 13]. Myeloid cells, such as monocytes and granulocytes, are pathologically activated by tumor-intrinsic inflammatory signals and acquire $\mathrm{T}$ cell suppressive functions [14]. This pathological activation led to the introduction of the functional classification of MDSC into monocytic (M)-MDSC and polymorphonuclear (PMN)MDSC [15].

MDSC promote tumor growth and metastasis via various mechanisms including PD-L1-dependent direct inhibition of $\mathrm{T}$ cell function and amino acid deprivation by arginase- 1 and iNOS [15-17]. Macrophages can either be polarized into a pro-inflammatory anti-microbial M1 state or into an anti-inflammatory tissue remodeling M2 state depending on the stimulus [18]. Based on that, similar mechanisms have been proposed for tumorassociated neutrophils (TAN), placing TGF- $\beta$ as an inducer of tumor-promoting N2 neutrophils [19] and IFN- $\beta$ as an inducer of anti-tumor N1 neutrophils [20]. Efforts to specifically target MDSC mostly focused on preventing recruitment and function by blocking stem cell or colony-stimulating factors, arginase- 1 or the iNOS pathway [21]. Thus, switching myeloid cells from a suppressive into an immune-supporting phenotype might serve as an option for restoring anti-tumor immunity. The FDA-approved vitamin A derivate all-trans retinoic acid (ATRA) has been shown to stimulate myeloid cell maturation into functionally active and $\mathrm{T}$ cell-promoting cells, thus, reprogramming the suppressive MDSC phenotype [22]. Another approach is the induction of type I IFN signaling in tumor hosts, which has been demonstrated to reduce the suppressive capacity of myeloid cells [23, 24].

IFN plays a central role in the immunogenicity of tumor cell death and it also seems to directly affect MDSC function [23, 25]. We could previously show that RIG-I-like helicases (RLH) induce a potent IFN-driven immune response with the induction of immunogenic tumor cell death. Stimulation with synthetic RLH ligands led to enhanced cross-presentation of tumor antigen by dendritic cells (DC) and a robust expansion of cytotoxic $\mathrm{T}$ cells $[26,27]$. RLH ligands have emerged as promising candidates for tumor immunotherapy and have entered phase I/Ib clinical trials for the treatment of advanced solid tumors (NCT03739138, NCT02828098). Moreover, modifications of the RIG-I ligands, combining siRNAtargeted gene silencing with RIG-I activation, have already been evaluated in preclinical models and show enhanced tumor control [28-30]. 
Here, we aim at characterizing the role of MDSC during RLH-based immunotherapy, using the MDA5/RLH ligand polyinosinic-polycytidylic acid poly(I:C), complexed to PEI (poly $(\mathrm{I}: \mathrm{C})_{\mathrm{c}}$ ) for intracellular delivery, in an orthotopic model of pancreatic cancer. Whole transcriptomic analysis of MDSC populations revealed an IFN pathway-enriched gene signature, accompanied by a shift from a M2/G2- towards a M1/G1-polarized phenotype. Using IFN receptor 1 (IFNAR1)-deficient mice, we show that IFNAR signaling may play an important role during MDSC development in tumor-bearing hosts, promoting a suppressive phenotype. Our data provide evidence that re-programming of MDSC via RLH-based immunotherapy contributes to unleashing $\mathrm{T}$ cell-mediated tumor control.

\section{Material and methods \\ Mice}

Female C57BL/6 mice were obtained from Janvier (France). All mice were kept with a 12-h light/dark cycle, water ad lib. and regular chow diet (sniff, Soest, Germany), at the University of Munich, Munich, Germany. The Kras $^{\text {G12D }}$ p53 ${ }^{\text {fl/R172H }}$ Ptf1a-Cre (KPC)-derived T110299 pancreatic tumor cell line was provided by Prof. Jens Siveke, (University Hospital Essen, Germany), Ifnar $1^{-/-}$ mice (Ifnar1 ${ }^{\text {tm1Agt }}$ ) were provided by Prof. Simon Rothenfußer (LMU Munich, Germany). Age- and sex-matched 6-12 weeks old wild type mice and OT-I TCR-transgenic mice $\left(C 57 B L / 6^{T g(T c r a T c r b) 1100 M j b / J}\right)$ were purchased from Jackson Laboratory (Stock number 003831).

\section{Cell culture}

Primary cells were cultured in RPMI-1640 medium (SigmaAldrich, Taufkirchen, Germany), supplemented with 10\% fetal calf serum (FCS), $2 \mathrm{mM} \mathrm{L}$-glutamine, $100 \mathrm{U} / 1$ penicillin, $0.1 \mathrm{mg} / \mathrm{ml}$ streptomycin, $100 \mathrm{mM}$ non-essential amino acids (all gibco ${ }^{\circ}$, Thermo Fisher Scientific, Karlsruhe, Germany), $1 \mathrm{mM}$ sodium pyruvate and $50 \mathrm{mM}$ 2-mercaptoethanol (both Sigma Aldrich). Tumor cells were cultured in DMEM high glucose media (Sigma-Aldrich), supplemented with 10\% FCS, $2 \mathrm{mM}$ L-glutamine, $100 \mathrm{U} / 1$ penicillin and $0.1 \mathrm{mg} /$ $\mathrm{ml}$ streptomycin. OVA expression T110299 cell were generated by transfection with the pAc-Neo-OVA plasmid [31] using the Novagen Genejuice ${ }^{\varpi}$ transfection reagent, according to the manufacturer's instructions. OVA+ T110299 cells were selected with G418 (geneticin). All cells were kept in a humidified incubator at $37^{\circ} \mathrm{C}$ and $5 \% \mathrm{CO}_{2}$. For the assessment of MHC-I expression of explanted tumors, we made use of EpCAM-expressing T110299 tumors cells, which were generated by transducing T110299 cell with a pMXs vector harboring murine EpCAM, thus, allowing labeling with $\mathrm{mAb}$ for flow cytometry analysis.
Orthotopic tumor induction and poly $(\mathrm{l}: \mathrm{C})_{\mathrm{c}}$ treatment Orthotopic tumors were induced by surgical implantation, as described before [28]. Briefly, mice were anesthetized and, by surgical incision, the pancreas was carefully mobilized for injection. After the injection of $2 \times 10^{5}$ T110299 cells in $25 \mu \mathrm{l} \mathrm{PBS}$, the pancreas was relocated and the incision was closed by surgical suture. Mice were monitored daily and distressed mice were sacrificed. For treatment, $50 \mu \mathrm{g}$ VacciGrade $^{\mathrm{Tm}} \mathrm{HMW}$ polyinosinic-polycytidylic acid (poly(I:C)) (InvivoGen, Toulouse, France) were complexed with in vivo-jetPEI ${ }^{\circ}$ (VWR International GmbH, Darmstadt, Germany), at a $\mathrm{N} / \mathrm{P}$ ratio of 6 in $5 \%$ glucose solution, according to the manufacturer's instructions (referred to as poly $(\mathrm{I}: \mathrm{C})_{\mathrm{c}}$ ). Mice were treated i.v. at day 18 and 20 after tumor induction with either poly(I:C $)_{c}$ or glucose as control. $6 \mathrm{~h}$ after the first treatment cytokine levels of CXCL10 and IL-6 were measured using enzyme-linked immunosorbent assays (ELISA) from R\&D systems (Minneapolis, USA). $12 \mathrm{~h}$ after the second treatment IFN $\beta$ levels were measured using ELISA from $R \& D$ systems. On day 14 and day 21 following tumor induction, serum G-CSF levels were measured by ELISA (R\&D systems, BioTechne GmbH, Wiesbaden-Nordenstadt, Germany). Tumor-free mice served as controls. All other serum cytokines were measured $6 \mathrm{~h}$ after the first treatment by multiplex analysis, using a Procarta Plex Mix\&Match Panel (Invitrogen, Thermo Fisher Scientific, Karlsruhe, Germany) and a MAGPIX ${ }^{\bowtie}$ system (Merck, Darmstadt, Germany), according to the manufacturer's protocol.

\section{Cell isolation}

Spleens were processed through a $70 \mu \mathrm{m}$ cell strainer, followed by red blood cell lysis (BD Pharm Lyse ${ }^{\mathrm{Tm}}$, BD Biosciences, Heidelberg, Germany). Tumor tissue was minced into pieces and mechanically dissociated using the mouse Tumor Dissociation Kit with the gentleMACS ${ }^{\mathrm{TM}}$ Dissociator application (both Miltenyi Biotech, Bergisch Gladbach, Germany), according to the manufacturer's instructions. The cell suspension was separated from tissue debris by sequentially using $100 \mu \mathrm{m}$ and $70 \mu \mathrm{m}$ cell strainers. For functional assays, $\mathrm{T}$ cells were isolated using the Pan T cell isolation Kit II and stained with $2.5 \mu \mathrm{M}$ CFSE (Thermo Fisher Scientific, Karlsruhe, Germany) for $4 \mathrm{~min}$ at room temperature. For MDSC isolation, the Myeloid-Derived Suppressor Cell Kit was used. Macrophages/TAM were isolated using the antiF4/80 MicroBeads UltraPure (all Miltenyi Biotec). Cell purity yielded $>95 \%$ for $\mathrm{T}$ cells, $60-95 \%$ for macrophages and 75 - 90\% for MDSC. For RNA analyses, single cell suspensions were enriched for myeloid cells using the $\mathrm{CD}_{11 \mathrm{~b}^{+}}$ MACS kit (Miltenyi Biotec) and stained with Fixable Viability Dye (eBioscience, Frankfurt, Germany), anti-CD45 (clone: 30-F11), anti-CD11b (clone: M1/70), anti-Ly6G (clone: 1A8) and anti-Ly6-C (clone HK1.4; all BioLegend, 
London, UK) for $30 \mathrm{~min}$ on ice. Cells were washed and

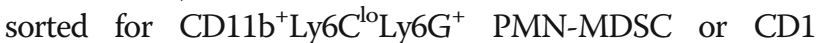
$1 b^{+}{ }^{2} 6 C^{\text {hi }}$ Ly6G $^{-}$M-MDSC on a BD FACSAria III (BD Biosciences), yielding mean purities of $>90 \%$ (tumor) and $>$ 95\% (spleen) (Additional file 1: Figure S3A).

\section{FACS analysis}

Prior to fluorochrome staining, FcRIII/II blocking was performed using the TrueStain $\mathrm{fcX}^{\mathrm{m}}$ antibody (Biolegend, London, UK). Cell surface staining was done with antiCD3 (clone 145-2C11), anti-CD4 (clone GK1.5), anti-CD8 (clone 53-6.7), anti-CD11b (clone M1/70), anti-CD11c (clone N418), anti-CD19 (clone 6D5), anti-CD26 (clone H194-112), anti-CD45 (clone 30-F11), anti-CD69 (clone H1.2F3), anti-CD172a (clone P84), anti-CD206 (clone C068C2), anti-EpCAM (clone G8.8), anti-F4/80 (clone BM8), anti-Ly6C (clone HK1.4), anti-Ly6G (clone 1A8), anti-MHC-I (clone AF6-88.5), anti-MHC-II (clone AF6120.01), anti-NK1.1 (clone PK136), anti-PD-1 (clone 29F.1A12), anti-PD-L1 (clone 10F.9G2), anti-CD86 (clone GL-1), anti-CD40 (clone 3/23), anti-XCR1 (clone ZET; all BioLegend, London, UK) and anti-CD204 (clone 2F8, Biorad, Munich, Germany) antibodies, and Fixable Viability Dye (Thermo Fisher Scientific, Karlsruhe, Germany) was used to exclude dead cells. The gating strategy is depicted in Additional file 1: Figure S1. Intracellular staining was done for arginase-1 (Polyclonal Sheep IgG; R\&D Systems, Minneapolis, USA) using the eBioscience ${ }^{\mathrm{m}}$ FoxP3/Transcription Factor Staining Buffer Kit (Thermo Fisher Scientific, Karlsruhe, Germany). Data were acquired on a BD LSRFortessa system (BD Bioscience, Heidelberg, Germany) and analyzed with FlowJo X software (FLOWJO LLC, Ashland, OR, USA).

\section{RNA sequencing}

RNA from MDSC and tumor tissue was isolated using the QIAzol Lysis buffer together with the RNeasy Kit (Qiagen, Hilden, Germany), according to the manufacturer's instructions. RNA concentration and rRNA integrity was measured using a Pico 6000 Assay (Agilent Technologies, Ratingen, Germany). RIN values were reached $>7$ (Additional file 1: Figure $\mathrm{S} 3 \mathrm{~A}$ ) and total RNA yield was $6.8-350 \mathrm{ng}$. RNA sequencing library was prepared using the SMARTer ${ }^{\circ}$ Stranded Total RNA-Seq Kit v2 - Pico-Input Mammalian (Takara, Saint-Germainen-Laye, France). Briefly, 10 ng RNA was fragmented for 4 min at $94{ }^{\circ} \mathrm{C}$, followed by first-strand cDNA synthesis following adding of Illumina Adapters and Indexes. RNA sequencing library was isolated using AMPure beads, and ribosomal RNA was depleted using ZapRv2 and R-Probes v2. RNAseq library was amplified in 13 cycles and isolated using AMPure beads. Mean tumor cell contamination, as determined by expression of cytokeratin
8 or 18 , was $<1 \%$, for tumor-derived MDSC populations (Additional file 1: Figure S3B).

\section{Bioinformatic data analysis}

Quality of sequencing reads was assessed using fastQC (http://www.bioinformatics. babraham.ac.uk/projects/fastqc). Reads were mapped against the mouse genome $(\mathrm{mm} 10)$ and mouse rRNA sequences with ContextMap version 2.7.9 [32], using BWA [33] as internal short read aligner and allowing at most 4 mismatches per read. Number of read fragments per gene were determined in a strand-specific manner from mapped RNA-Seq reads, using featureCounts [34] and Gencode (v16) annotations. Gene expression was quantified as numbers of fragments per kilobase of transcript per million mapped reads (FPKM). Principal component analysis (PCA) was performed in $\mathrm{R}$ for all genes with a median FPKM $\geq 1$, for conditions compared. Differential gene expression analysis was performed on gene read counts using DEseq2 for all genes with an average of 25 reads per sample [35]. P-values were adjusted for multiple testing using the method by Benjamini and Hochberg [36], and genes with an adjusted $p$-value $<0.001$ and at least a 2 -fold change in expression (fold-change $\geq 2$ or $\log 2$ fold-change $\leq 1 / 2$ ) were considered significantly differentially expressed. The RNA-Seq analysis workflow was implemented and run using the workflow management system Watchdog [37]. Gene set enrichment analysis for all genes ranked by gene expression $\log 2$ fold-change was performed using GSEA [38] for MSigDB gene sets (FDR q-value cutoff 0.05):

GSE24102_GRANULOCYSTIC_MDSC_VS_NEUTROPHIL_DN/UP, GSE5099_CLASSICAL_M1_VS_ALTERNATIVE_M2_MACROPHAGE_DN/UP, GSE5099_MONOCY TE_VS_CLASSICAL_M1_MACROPHAGE_DN/UP.

Functional enrichment analysis for up- and downregulated genes was performed using the DAVID webserver [39], against the background of all genes included in the differential gene expression analysis (adj. p-value $<0.01$ ).

\section{qRT-PCR}

Total RNA was isolated using the peqGold TriFast ${ }^{\text {Tw }}$ Kit (VWR International GmbH, Darmstadt, Germany) according to the manufacturer's instructions. cDNA synthesis was done with the RevertAID ${ }^{m}$ First strand cDNA Synthesis kit (Thermo Fisher Scientific, Karlsruhe, Germany) and qRTPCR was performed with KAPA PROBES FAST qPCR Maser Mix (2x) Kit (Sigma-Aldrich, Taufkirchen, Germany), on the LightCycler 480 II system (Roche Diagnostics, Penzberg, Germany). Primers were designed with the Universal Probes Library.

\section{T cell suppression assay}

For the assessment of suppressive capacity of MDSC or macrophages, a co-culture with $\mathrm{T}$ cells was done. For 
this, $5 \times 10^{4}$ CFSE-labeled T cells (per well) from tumornaïve C57BL/6 mice were seeded into 96-well plates and co-cultured with $1.25 \times 10^{4}(0.25: 1), 2.5 \times 10^{4}(0.5: 1)$ or $5 \times 10^{4}(1: 1)$ MDSC or macrophages. Each well was supplemented with $1 \mu \mathrm{l}$ anti-CD3/anti-CD28 mAb-coated beads (gibco ${ }^{\circ}$, Thermo Fisher Scientific, Karlsruhe, Germany). After $72 \mathrm{~h}$, CFSE dilution of $\mathrm{CD} 4^{+}$and $\mathrm{CD} 8^{+}$ $\mathrm{T}$ cells was analyzed by flow cytometry. IFN- $\gamma$ secretion following co-culture was measured from supernatants at an E:T ratio of 1:1, with ELISA (BD OptEIA, BD Biosciences, Heidelberg, Germany).

\section{Antigen presentation assay}

To assess antigen presentation of MDSC, $5 \times 10^{4}$ CFSElabeled OT-I T cells were seeded into 96-well plates and co-cultured with $1.25 \times 10^{4}(0.25: 1), 2.5 \times 10^{4}(0.5: 1)$ or $5 \times 10^{4}$ (1:1) MDSC. Tumor-derived MDSC were cocultured without further treatment. Splenic MDSC were incubated with $1 \mu \mathrm{g} / \mathrm{ml} \mathrm{OVA}$ protein over night at $37^{\circ} \mathrm{C}$ or loaded with SIINFEKL $(100 \mu \mathrm{g} / \mathrm{ml})$. Subsequently, MDSC were washed and seeded as described above. After $72 \mathrm{~h}$, CFSE dilution of $\mathrm{CD}^{+} \mathrm{T}$ cells was analyzed by flow cytometry.

\section{Statistical analysis}

Data present means +/- standard error of the mean (SEM) of biological replicates. Significant differences between two groups were calculated using the Mann Whitney $U$ test or if indicated using an unpaired two-sided students $\mathrm{t}$ test. Multiple comparisons were analyzed using Kruskal Wallis test. In case of significant results, subsequent post hoc test was calculated for selected comparisons as indicated. Spearman's rank-order correlation was performed to analyze associations. To analyze the influence of genotype and treatment a 2-way ANOVA was performed. In case of a significant result, post hoc test between treatments was performed as indicated. Statistical analysis was performed using GraphPad Prism software (version 7.04); $p$-values $<0.05$ were considered significant.

\section{Results}

\section{KPC-derived PDAC is characterized by infiltration with} myeloid cells and a T cell-deprived TME

The KPC-derived T110299 PDAC mouse model shares many pathological features observed in human disease. As such, we investigated the impact of T110299 tumors on myelopoiesis, the TME and its immune cell composition. Tumor cells were implanted into the pancreas of syngeneic C57BL/6 mice and subsequently, immune cell composition in blood, spleen and tumors was monitored within 21 days of tumor development. Tumor engraftment was evident within the first week and progressed rapidly during the following 2 weeks. Tumor growth was paralleled by splenomegaly without any signs of metastasis, indicating influx or proliferation of hematopoietic cells (Fig. 1a-b). Analysis of immune cell composition (Additional file 1: Figure S1) during tumor progression revealed an expansion of myeloid cells in blood, spleen and tumor. The expansion of the myeloid compartment was most pronounced in tumor tis-

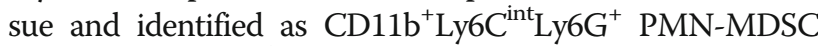

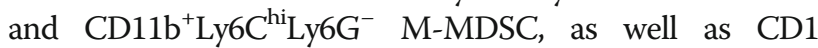
$1 \mathrm{~b}^{+}$Ly6C $\mathrm{C}^{\text {low/int }} \mathrm{F} 4 / 80^{+}$macrophages, as major cell populations (Fig. 1c). In tumors, myeloid cell recruitment (macrophages, PMN-MDSC and M-MDSC) preceded $\mathrm{T}$ cell infiltration, with $\mathrm{T}$ cells transiently peaking on day 14 . On day 21 , the immune cell infiltrate was dominated by macrophages and PMN-MDSC. Correlation analysis further revealed a strong correlation between tumor size and PMN-MDSC expansion, both systemically and in tumor tissue (Fig. 1d). Overall, we predominantly observed increased PMN-MDSC populations with increased tumor weight in blood, spleen and tumor, whereas blood $\mathrm{CD}^{+} \mathrm{T}$ cells as well as tumor-resident NK cells decreased (Fig. 1e). We also investigated in more detail the role of the growth factor G-CSF, which is produced by KPC-derived PDAC and known to induce proliferation of granulocytic precursor cells in tumor bearing hosts [13]. In our PDAC model, serum levels of G-CSF were increased in tumor-bearing mice, and highly correlated with PMN-MDSC populations in blood and spleen, as well as with tumor weight, suggesting G-CSF to be a major driver for the expansion of PMNMSC with a strong immunosuppressive phenotype (Fig. 1f).

The inverse correlation of MDSC and T cell infiltration during PDAC progression prompted us to characterize immune suppressive mechanisms of the TME. Within the MDSC compartment, we investigated the expression of known immune suppressive mediators, such as arginase-1 and the checkpoint molecule PD-L1. Arginase-1 levels were comparably low in splenic PMNand M-MDSC during tumor development, but highly upregulated in tumor-resident MDSC (Fig. 1g). Similar characteristics were also found for PD-L1 expression (Fig. 1h). Moreover, the PD-L1 counterpart, PD-1, was expressed on the vast majority of tumor-resident $\mathrm{CD} 8^{+}$ and $\mathrm{CD} 4^{+} \mathrm{T}$ cells (Fig. 1i). Subsequently, we assessed the ability of MDSC to inhibit T cell activation, which is the population-defining hallmark of MDSC. We isolated MDSC populations from spleen and tumors to set up a co-culture with anti-CD3/CD28 mAb-activated $\mathrm{T}$ cells from tumor-free mice, and used monocytes and granulocytes isolated from spleens of tumor-free mice as controls. Only MDSC from PDAC-bearing mice displayed pronounced suppressive effects on $\mathrm{CD}^{+}$as well as $\mathrm{CD}^{+}{ }^{+} \mathrm{T}$ cell proliferation. Whilst PMN-MDSC turned out to be more suppressive than M-MDSC, overall MDSC populations isolated from tumors exhibited the most pronounced suppressive capacity (Fig. 1j). Together, the data show that KPC-derived PDAC develop 


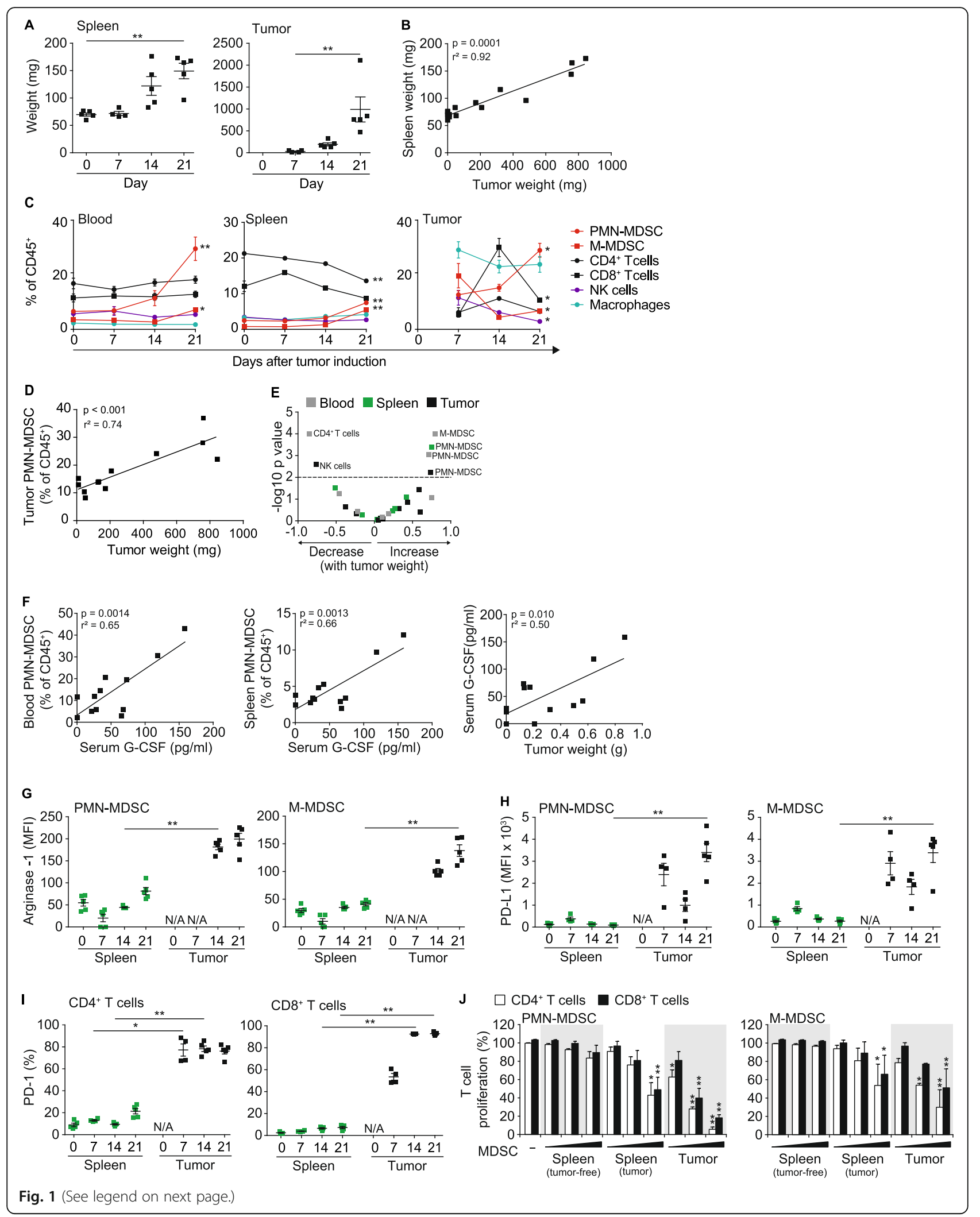


(See figure on previous page.)

Fig. 1 KPC-derived PDAC is characterized by infiltration with myeloid cells and a T cell-deprived tumor microenvironment (TME). T110299 tumors were implanted orthotopically in syngeneic C57BL/6 mice which were sacrificed at days 7, 14 and 21 after tumor induction for analysis of blood, spleen and tumor. a-b Spleen and tumor weights and respective correlation analysis. c Relative frequency of leukocytes in blood, spleen and tumor. $\mathbf{d}$-e Correlation of relative immune cell frequency with tumor weight. $\mathbf{f}$ Correlation of serum G-CSF level with PMN-MDSC frequency in blood and spleen as well as correlation of tumor weight with G-CSF level in serum. $\mathbf{g}-\mathbf{h}$ Surface expression of arginase-1 and PD-L1 on MDSC. $\mathbf{i}$ PD-1 expression on T cells in spleens and tumors. $\mathbf{j}$ MDSC-like cells from naïve mice as well as MDSC from spleens and tumors of tumor-bearing mice were isolated and co-cultured with CFSE-labeled T cells in increasing effector ( $E$; MDSC) to target (T; T cell) ratios (E:T) of 0.25:1, 0.5:1 and 1:1, in the presence of anti-CD3/anti-CD28 mAb-coated beads. After $72 \mathrm{~h}$ CFSE dilution of T cell populations was assessed. a,c,g,h,i Data \pm SEM is shown for $n=4-5$ mice per group. $\mathbf{b}, \mathbf{d}, \mathbf{f} n=12$ mice (e) $n=12$ mice / group (c) Statistics for the comparison of day 0 and day 21 (blood and spleen), and day 7 and day 21 (tumor) are shown. (j) Representative graph of three independent experiments, Data \pm SEM for $n=2$ mice per group, unpaired two-sided students t test $\left({ }^{*} p<0.05,{ }^{* *} p<0.01\right.$, in J compared to tumor-free control)

typical features of a suppressive TME characterized by pathologically activated myeloid cells with high suppressive capacity.

\section{Poly $(\mathrm{l}: \mathrm{C})_{\mathrm{c}}$ reduces tumor mass in PDAC concomitant with enhanced $\mathrm{T}$ cell activation and reduced suppressive capacity of MDSC}

We showed earlier that a systemic therapy with the MDA5 ligand poly $(\mathrm{I}: \mathrm{C})_{\mathrm{c}}$ had a positive effect on survival of PDAC-bearing mice, which was dependent on the presence of cytotoxic $\mathrm{T}$ cells [27]. Other studies with RLH ligands pointed towards a reduced number or altered function of MDSC in treated animals [24, 28, 40]. To study the effect of RLH activation on MDSC in fully established tumors in more detail, we treated mice with poly $(\mathrm{I}: \mathrm{C})_{\mathrm{c}}$ i.v. and analyzed the tumors 21 days after tumor induction. Treatment resulted in a $50 \%$ reduction in tumor mass (Fig. 2a). Downregulation of MHC class I is a common mechanism of tumors to evade the immune system. We could previously show that stimulation of pancreatic cancer cells in vitro with RLH ligands induces the up-regulation of MHC-I as well as CD95 (Fas), resulting in more effective tumor cell killing by cytotoxic $\mathrm{T}$ cells [26]. In line with these in vitro findings, poly $(\mathrm{I}: \mathrm{C})_{\mathrm{c}}$ led to a profound upregulation of MHC-I molecules on tumor cells in vivo (Fig. 2a). RLH ligands are strong inducers of type I IFN, which in turn mounts a robust immune response connecting innate with adaptive immunity. As such, RLH treatment resulted in high levels of CXCL10 and IFN- $\beta$, which were accompanied by $\mathrm{T}_{\mathrm{h}} 1$-supporting IL-12p70 and IFN-y as well as IL-28, an important type III IFN further supporting CTLmediated cytotoxicity (Fig. 2b).

We observed a relative reduction of PMN-MDSC, whereas M-MDSC frequency increased in both spleen and tumor (Fig. 2c). Analysis of MDSC surface marker expression revealed a strong therapy-mediated PD-L1 induction in spleen. Similar to our earlier observations in treatment-naïve mice, we found high basal PD-L1 expression by MDSC within the tumor tissue, which was not further increased by immunotherapy (Fig. 2d). T cell frequencies in spleens were unaltered; however, increased infiltration of $\mathrm{CD}^{+} \mathrm{T}$ cells was detected within the tumor tissue, which is in line with our previous observations (Fig. 2e). Both splenic and tumorinfiltrating $\mathrm{T}$ cells upregulated expression of the early activation marker CD69 in response to poly $(\mathrm{I}: \mathrm{C})_{\mathrm{C}}$, whereas PD-1 expression was unaffected (Fig. 2f-g). We then assessed whether poly $(\mathrm{I}: \mathrm{C})_{\mathrm{c}}$ treatment affects the suppressive capacity of MDSC. We isolated MDSC populations from spleen and tumor of untreated and treated PDAC-bearing mice and studied their influence on $\mathrm{T}$ cell proliferation. In order to assess overall immunosuppressive effects of MDSC $\mathrm{T}$ cell response, we measured IFN- $\gamma$ secretion as key cytokine of T cell activation in MDSC co-cultures. As expected, at an effector (MDSC) to target (T cell) ratio of 1:1, IFN- $\gamma$ secretion was strongly suppressed by MDSC (Fig. 2h); however, this was - at least in parts - rescued in co-cultures with MDSC from mice previously treated with poly $(\mathrm{I}: \mathrm{C})_{\mathrm{c}}$. As observed before, tumor-derived MDSC were more suppressive compared to their splenic counterparts, with the highest suppression seen in PMN-MDSC co-cultures, for both $\mathrm{CD}^{+}$ and $\mathrm{CD}^{+} \mathrm{T}$ cells. Suppressive function of MDSC populations from poly $(\mathrm{I}: \mathrm{C})_{\mathrm{c}}$-treated animals was reduced for both, PMN-MDSC and M-MDSC (Fig. 2i). These findings are indicative of a functional in vivo reprogramming of MDSC in poly $(\mathrm{I}: \mathrm{C})_{\mathrm{c}}$-treated mice.

Analysis of splenic and tumor-resident B and NK cells showed a slight increase in splenic B cell numbers; both cell populations upregulated CD69 expression upon therapy (Additional file 1: Figure S2A-B). Poly(I:C) treatment increased both the intratumoral frequency of migratory cross-presenting conventional DC 1 (cDC1) as well as their activation measured by CD40 expression. In addition, the co-stimulatory molecule CD86 was upregulated in both $\mathrm{CD} 11 \mathrm{c}^{+} \mathrm{MHC}-\mathrm{II}^{\mathrm{hi}} \mathrm{CD} 26^{+} \mathrm{XCR} 1^{+} \mathrm{CD} 172 \mathrm{a}^{-}$ $\mathrm{cDC} 1$ and $\mathrm{CD} 11 \mathrm{c}^{+} \mathrm{MHC}-\mathrm{II}^{\mathrm{hi}} \mathrm{CD} 26^{+} \mathrm{CD} 172 \mathrm{a}^{+} \mathrm{XCR} 1^{-} \mathrm{cD}$ $\mathrm{C} 2$ in the tumor-draining lymph node (Additional file 1: Figure S2C-D). Interestingly, the relative frequency of macrophages/TAM was significantly reduced in treated animals, in both spleen and tumor. Moreover, macrophages/TAM showed an activated phenotype with enhanced MHC-I expression (Additional file 1: Figure S2EG). Further analyses revealed that the frequency of M2like $\mathrm{CD}_{204} \mathrm{CD}^{+} 26^{+}$macrophages, known to highly 


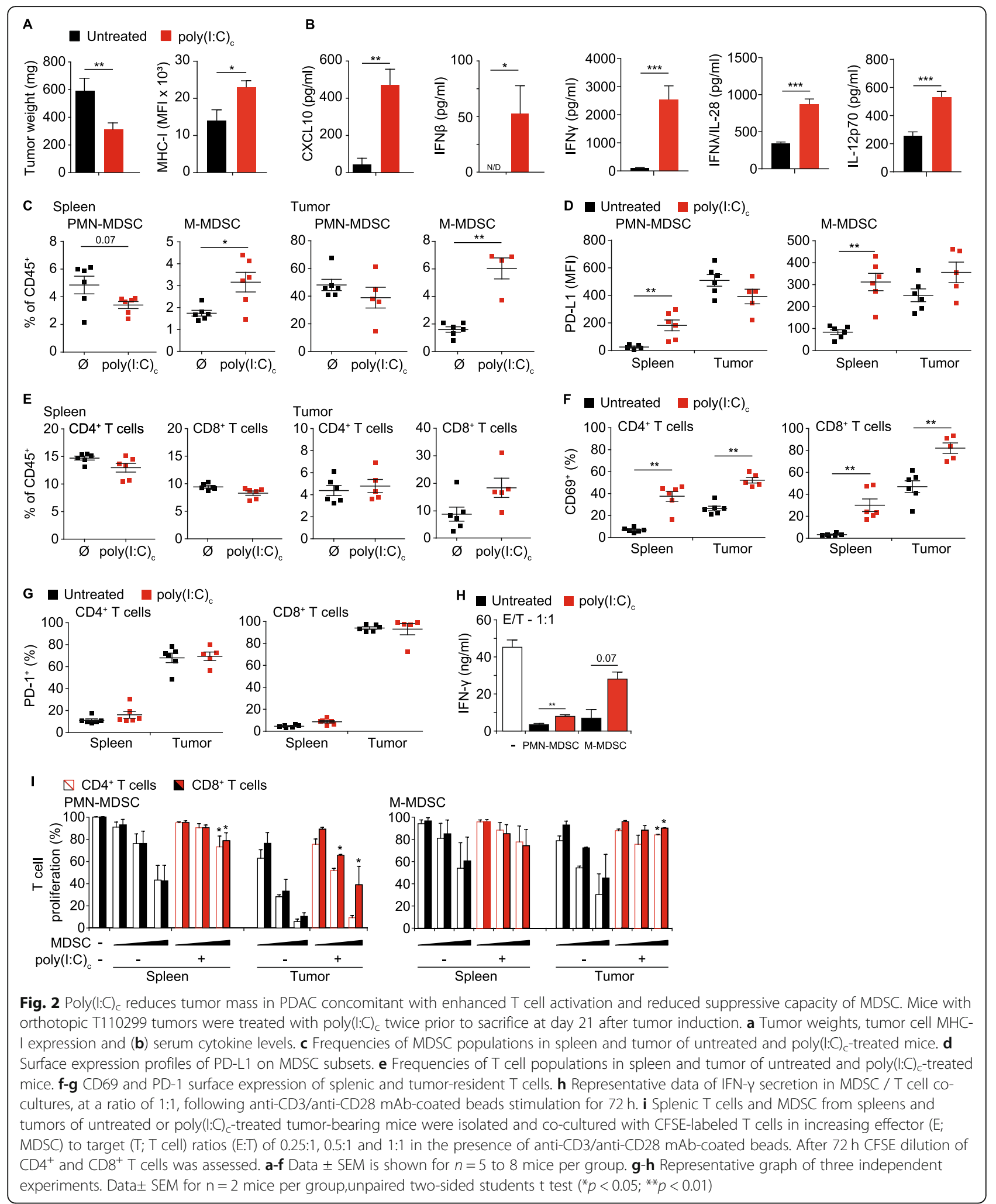

correlate with poor disease outcome in patients with various cancer types [41-43], was decreased in tumors (Additional file 1: Figure S2E-F). TAM showed a strong $\mathrm{T}$ cell suppressive phenotype, which was in contrast to MDSC - not reversed upon poly $(\mathrm{I}: \mathrm{C})_{\mathrm{c}}$ treatment (Additional file 1: Figure $\mathrm{S} 2 \mathrm{H}$ ). 


\section{Transcriptomic profiling reveals a therapy-induced reprogramming of MDSC}

To better understand the mechanisms by which MDSC undergo phenotypical changes upon systemic immunotherapy, we performed a whole transcriptome analysis of PMN- and M-MDSC populations from spleens and tumors. Mice with orthotopic PDAC were treated on day 18 and 20 after tumor implantation with poly $(\mathrm{I}: \mathrm{C})_{\mathrm{c}}$ or were left untreated. On day 21, MDSC were sorted for high purity (Additional file 1: Figure S3A-B), followed by RNA extraction and next-generation sequencing. An unbiased principle component analysis (PCA), using the
14.000 most expressed genes, was performed. For both PMN- and M-MDSC, the replicates of each condition clustered closely, confirming the high quality of the data. PCA revealed that PC1 distinguishes samples based on the compartment they were isolated from (PMN-MDSC: 44.3\%; M-MDSC: 25.5\%), and PC2 described the changes that were induced by poly $(\mathrm{I}: \mathrm{C})_{\mathrm{c}}$ treatment $(\mathrm{PMN}-\mathrm{MDSC}$ : 10.5\%; M-MDSC: 15.6\%) (Fig. 3a). The 1000 genes contributing most to PC2 in PMN- and M-MDSC show a similar regulation in both spleen and tumor (Fig. 3b).

The treatment-induced transcriptomic changes were analyzed by a differential gene expression analysis (adjusted

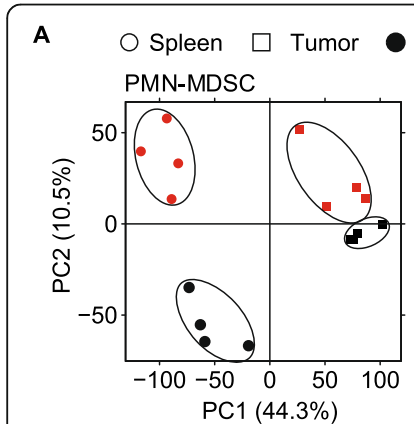

c

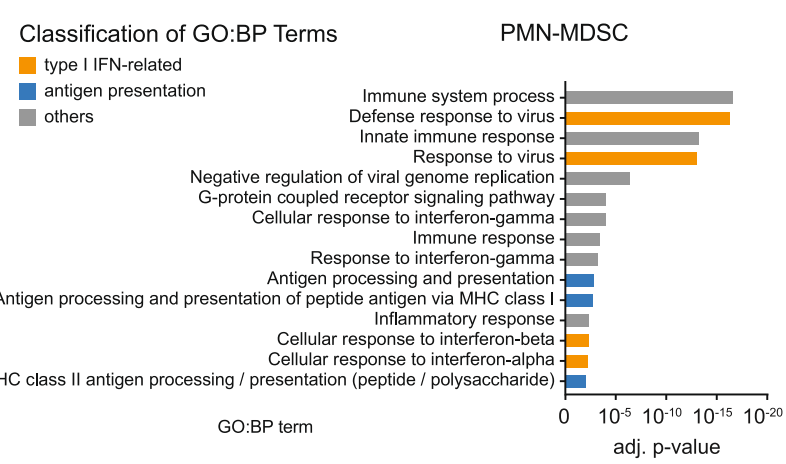

D

PMN-MDSC

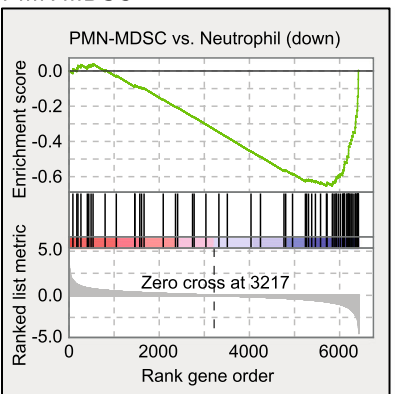

M-MDSC

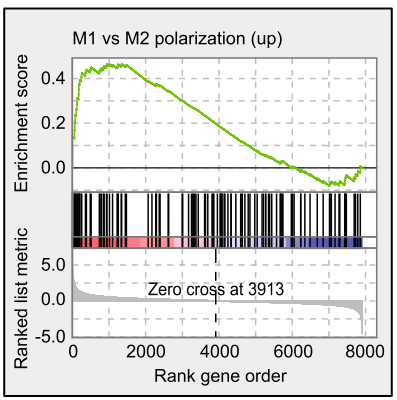

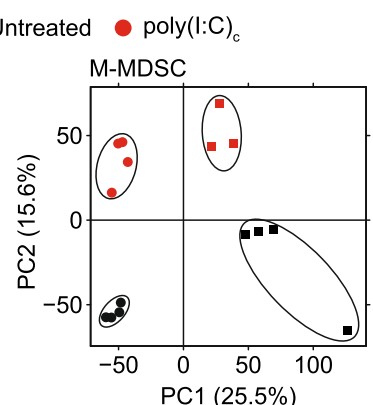
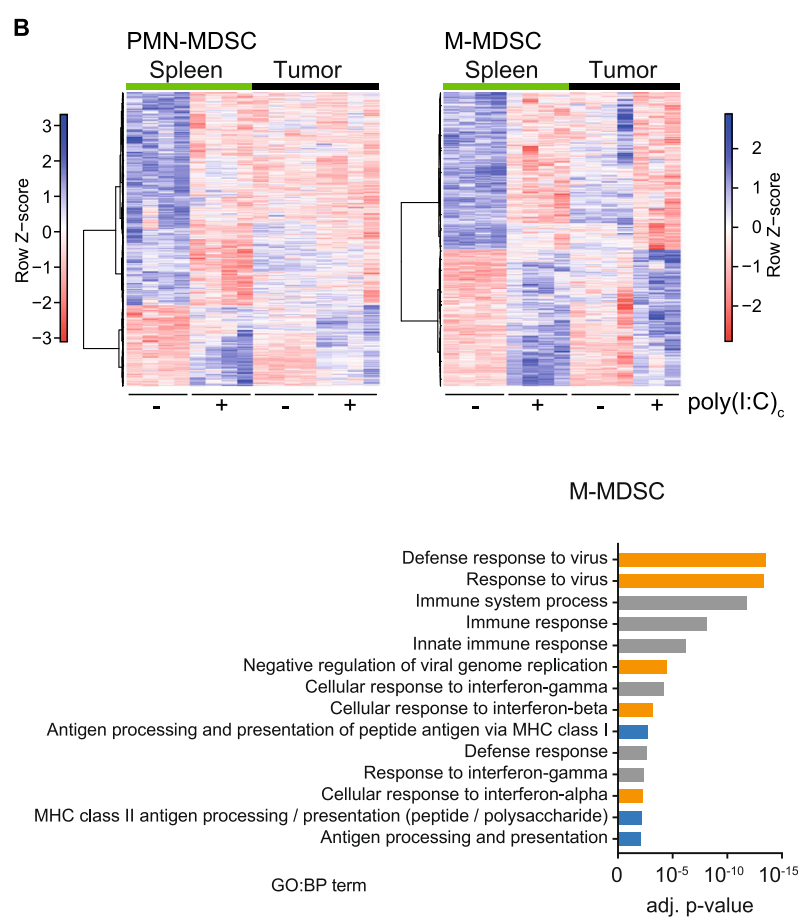

Fig. 3 Poly $(l: C)_{c}$ triggers transcriptional reprogramming of MDSC. Mice with orthotopic T110299 tumors were treated twice with poly(l:C $)_{c}$ prior to sacrifice as described before. RNA of MDSC populations was isolated for whole transcriptome analysis. a Principal component analysis (PCA) of transcriptome of splenic or tumor-derived MDSC with and without poly $(I: C)_{c}$ treatment. b Heatmap of gene expression values (colors indicate row z-scores) for the 1.000 genes contributing most to principle component 2 (PC2). c DAVID analysis for enriched gene ontology biological processes (GO:BP) terms from differentially expressed genes (adjusted $p<0.001, \geq 2$-fold change) upon poly $(\mathrm{l}: \mathrm{C})_{c}$ treatment from splenic MDSC. $\mathbf{d}$ Gene set enrichment analysis (GSEA) of differentially expressed genes upon poly(l:C) treatment compared to published gene sets describing PMN-MDSC vs. neutrophils (GSE24102) and macrophage polarization (GSE5099). Data shown for $n=3$ to 4 mice per group 
$p<0.001, \geq 2$-fold change) in PMN-MDSC (spleen: 420; tumor: 180; shared: 100) and M-MDSC (spleen: 584; tumor: 210; shared: 113) (Additional file 1: Figure S3C). Functional annotation analysis using the Database for Annotation, Visualization and Integrated Discovery (DAVID) was done with differentially expressed genes from spleen. Genes were found to be significantly enriched in gene ontology biological process (GO:BP) clusters related to immune system processes, virus and IFN response-related pathways, and antigen presentation-related genes (Fig. 3c and Additional file 1: Figure S4). Most importantly, gene set enrichment analysis of splenic differentially expressed genes revealed an enrichment of neutrophil-associated gene signature for PMN-MDSC and enrichment of M1associated genes for M-MDSC after poly(I:C) ${ }_{c}$ therapy, suggesting the phenotypic reprogramming of MDSC (Fig. 3d).

\section{MDSC of treated mice do not acquire professional antigen presenting cell function}

One of the significantly enriched gene clusters was associated with MHC class-I antigen presentation. In both PMN- and M-MDSC, essential components of the MHC-I-dependent antigen processing and presentation machinery, including the immunoproteasome, the peptide transporter TAP and the MHC-I complex, were upregulated following poly $(\mathrm{I}: \mathrm{C})_{\mathrm{c}}$ therapy (Fig. 4a-b). Flow cytometric analysis revealed a therapy-induced upregulation of MHC-I expression for PMN-MDSC in spleen and tumor, and for M-MDSC in spleen only (Fig. 4c). Moreover, upregulation of the costimulatory molecule CD86 was observed in a subset of splenic PMN-MDSC and the majority of M-MDSC. Tumor-resident MMDSC already expressed high levels of CD86 and remained unaltered upon therapy (Fig. 4d).

To investigate the ability of MDSC to present tumorassociated antigen on MHC-I, ovalbumin (OVA)-expressing T110299 tumors (T110299-OVA) were used as model. 18 and 20 days after tumor induction, mice were treated with poly $(\mathrm{I}: \mathrm{C})_{\mathrm{c}}$ or left untreated and MDSC from both tumor and spleen were isolated. Tumor-derived PMN- and $\mathrm{M}-\mathrm{MDSC}$ were unable to induce antigen-dependent $\mathrm{CD} 8^{+}$ $\mathrm{T}$ cell proliferation, irrespective of treatment (Fig. 4e). In Addition, we evaluated the capability of MDSC to process and cross-present OVA protein ex vivo. Splenic MDSC from T110299-OVA tumor-bearing hosts were incubated overnight with OVA protein and subsequently co-cultured with OT-I T cells for 3 days. Again, no T cell proliferation was detectable (Fig. 4f). To rule out that the lack of functional cross-presentation is due to $\mathrm{T}$ cell inhibition by MDSC, the presentation of exogenously added SIINFEKL peptide was assessed. For this, MDSC of T110299-OVA tumor bearing hosts were isolated, pulsed with SIINFEKL peptide and subsequently co-cultured with OT-I T cells.
Peptide-loaded MDSC were able to induce a strong OT-I $\mathrm{T}$ cell proliferation, with no detectable differences between MDSC of untreated or treated mice (Fig. 4g). Together, these data rule out a function of MDSC as professional antigen presenting cells, which was irrespective of their polarization status.

\section{Therapeutic efficacy and immune activation of MDA5- targeted immunotherapy is mediated by type I IFN signaling}

MDA5 activation is known to induce type I IFN and the transcriptomic profile of MDSC in poly $(\mathrm{I}: \mathrm{C})_{\mathrm{C}}$ treated mice confirmed a predominant type I IFN response. To further evaluate the role of IFN signaling on MDSC function and tumor control, therapeutic efficacy of poly $(\mathrm{I}: \mathrm{C})_{\mathrm{c}}$ treatment was assessed in PDAC-bearing wild-type and IFNAR1deficient mice.

Tumor weight was significantly decreased in wild-type mice after poly $(\mathrm{I}: \mathrm{C})_{\mathrm{c}}$ treatment, whereas no difference was observed in Ifnarl ${ }^{-1-}$ mice, supporting a role of IFN signaling as a prerequisite for anti-tumor efficacy (Fig. 5a). As expected, CXCL10 serum levels of both wild-type and Ifnar $1^{-/-}$mice were comparable after treatment; however, IL-6 serum levels were significantly decreased in Ifnar $1^{-/-}$ mice (Fig. 5a). Untreated mice had comparable frequencies of MDSC and poly $(\mathrm{I}: \mathrm{C})_{\mathrm{c}}$ treatment led to a decrease of PMN-MDSC and an increase of M-MDSC numbers in wild-type mice, but not Ifnar ${ }^{-/-}$mice (Fig. 5b). Furthermore, MDSC from IFNAR1-deficient mice failed to upregulate MHC-I and PD-L1 expression upon therapy, indicating a critical role for IFN signaling on MDSC numbers and phenotype upon MDA5-based immunotherapy (Fig. 5c-d). Neither the genotype nor the treatment had an influence on $\mathrm{CD}^{+}$and $\mathrm{CD} 8^{+} \mathrm{T}$ cell frequencies in spleen and tumor; however, poly $(\mathrm{I}: \mathrm{C})_{\mathrm{c}}$ failed to induce CD69 expression in $\mathrm{T}$ cells of Ifnar ${ }^{-1-}$ mice (Fig. 5e-f).

Our data show that MDA5-based immunotherapy in PDAC-bearing mice led to a reduction of the suppressive function of MDSC populations, concomitant with a dominant IFN signature in their transcriptomic profile. We therefore investigated the role of type I IFN signaling on the suppressive capacity of MDSC in Ifnarl ${ }^{-/-}$ mice. Interestingly, in untreated tumor-bearing hosts the suppressive capacity of MDSC was reduced in Ifnar ${ }^{-/-}$ mice, as compared to their wild-type controls, pointing towards a role for IFN signaling in early MDSC differentiation into a suppressive phenotype (Fig. $5 \mathrm{~g}$ ). Of note, while poly $(\mathrm{I}: C)_{\mathrm{c}}$ treatment reversed the suppressive capacity of MDSC in wild-type mice, the $\mathrm{T}$ cell suppressive function of both PMN- and M-MDSC from Ifnar ${ }^{-/-}$ mice was not significantly changed, arguing for a role of IFN signaling in regulating the suppressive function upon MDA5-based therapy. 


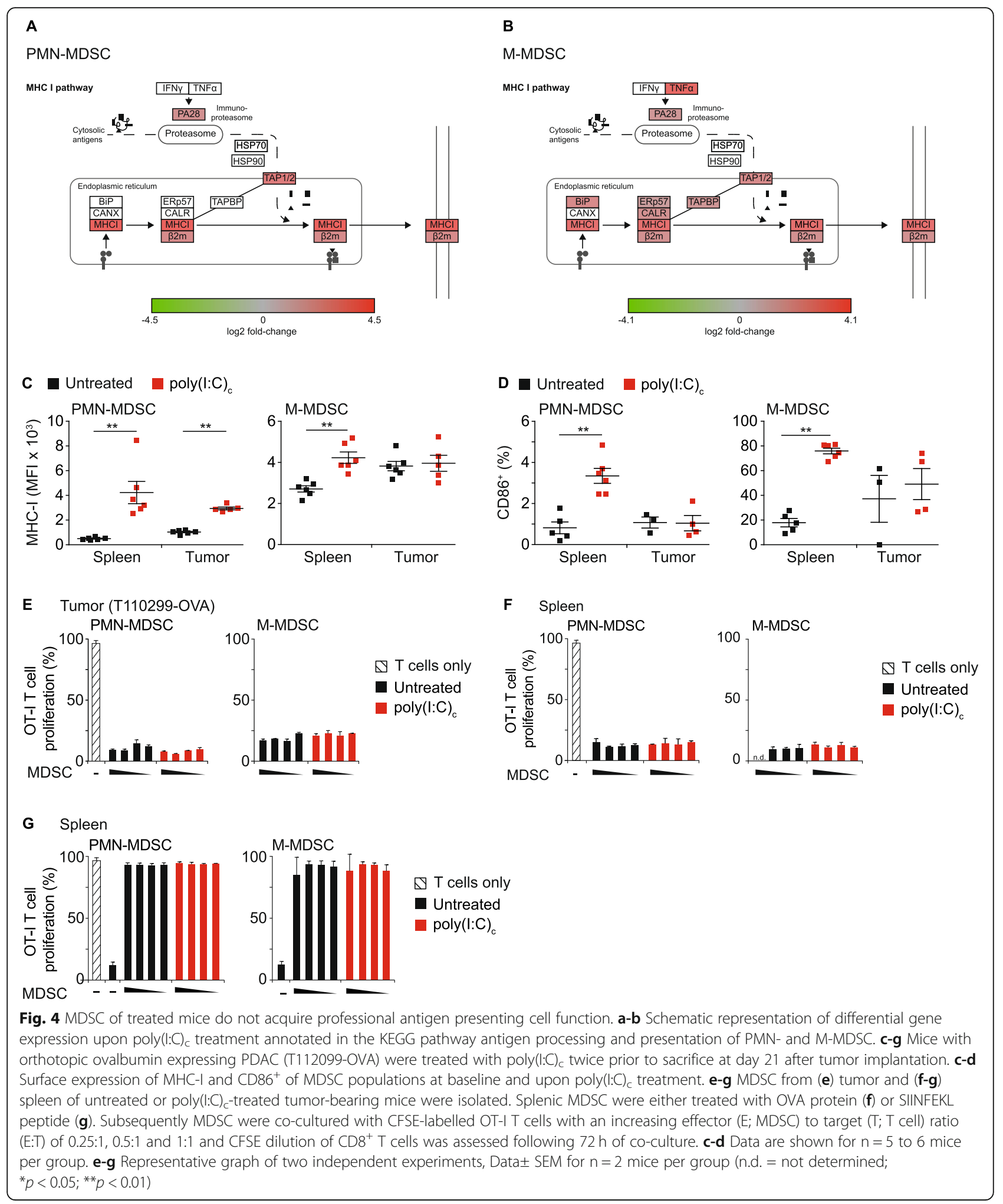

\section{Discussion}

PDAC remains poorly responsive to many therapies and one major hurdle is the immunosuppressive TME that is created during PDAC progression [2]. MDSC have attracted the field of tumor immunotherapy and are accepted as important factors in shaping the TME. MDSC actively contribute to the TME to preserve an immunologically compromised state. Due to their plasticity, 


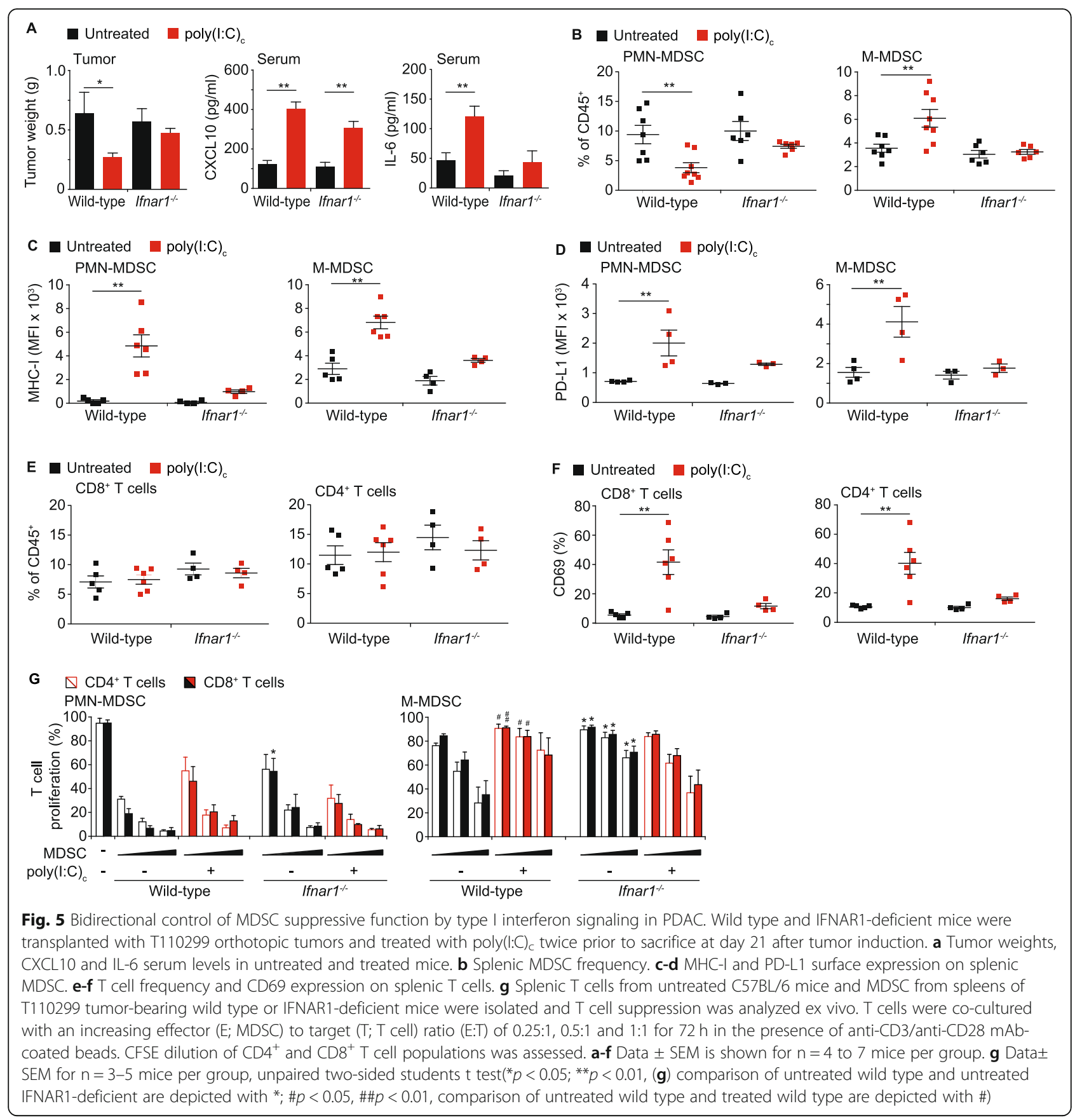

targeting MDSC is difficult and strategies mainly focused on altering recruitment and function [21]. Human and mouse MDSC share similar features, which underlines the importance of translational mouse models as important source to develop novel targeting approaches.

We made use of an KPC-derived orthotopic pancreatic cancer model [44] and show that PDAC develop an immunosuppressive TME characterized by dense infiltration with MDSC and sparse T cell recruitment. During tumor growth, the frequency of PMN-MDSC increased systemically. Similar as observed for human disease,
MDSC showed a pathologic activation with enhanced levels of arginase-1 and PD-L1, high T cell suppressive capacity, and compartmentalized differences accentuating tumor-resident MDSC with increased suppressive activity $[17,45]$. Using the KPC-derived pancreatic cancer model, we observed a more potent suppressive capacity of PMN-MDSC as compared to M-MDSC. The pathological activation of PMN-MDSC is a hallmark of KPC-derived pancreatic cancer, a finding that is covered by a recent report of $\mathrm{Li}$ et al. in a similar tumor model, demonstrating PMN-MDSC as key determinants of the 
immunosuppressive TME [46]. The literature provides evidence for both MDSC populations bearing strong suppressive capacity [47-49].

During tumor progression, the tumor induces a highly complex secretome, which is characteristic for the TME and for entertaining the suppressive phenotype by accelerated myelopoiesis, impaired differentiation, and enhanced pathological activation of MDSC. In PDAC the TME is characterized by high levels of growth factors (e.g. G-CSF, GM-CSF) and cytokines (e.g. IL-6, TGF- $\beta$ ), accounting for the chronic inflammatory and suppressive phenotype [50]. It is conceivable that such tumor-derived signals are able to program myeloid cells towards an tumor-promoting phenotype, with systemic effects targeting spleen and bone marrow. A crucial factor involved in the generation and pathological activation of PMN-MDSC is the growth factor G-CSF, and systemic levels of G-CSF have been correlated with MDSC accumulation in several tumor models $[46,51,52]$. We speculate that G-CSF also accounts for the pathological activation of PMN-MDSC in KPCderived pancreatic cancer, as elevated G-CSF serum levels during tumor progression correlated with the frequency of PMN-MDSC in spleen and blood. Thus, blocking G-CSF signaling could provide a means to alleviate MDSCmediated immune suppression.

Preclinical data and early clinical trials showed that preventing the accumulation of PMN- and M-MDSC by blocking the CXCR2- and CCR2-dependent migration, respectively, might serve as strategy to change the immunosuppressive TME [53]. We sought to investigate the effects of an RLH-based immunotherapy as approach for reprogramming an immunosuppressive into a therapyvulnerable "hot" TME [11]. We could earlier show that mimicking a viral infection by the injection of synthetic RLH ligands augmented anti-tumor immunity and greatly induced an immunogenic form of tumor cell death [26]. The RLH-targeting therapy broadly altered the cellular immune landscape in spleens and tumors, which also included alterations within MDSC populations [28]. We previously reported that the MDA5-based therapeutic efficacy in PDAC is mediated by $\mathrm{CD}^{+} \mathrm{T}$ cells [27]. Here, we show that systemic $\mathrm{T}$ cell activation and concomitant tumor reduction are dependent on intact IFNAR signaling. This has also been confirmed in melanoma studies showing that both lymphoid and myeloid IFNAR signaling is critical for the therapy response, underlining the central role for IFN in anti-tumor immunity $[54,55]$.

We found that the change in peripheral MDSC frequency upon therapy was dependent on IFNAR1 signaling. An IFN-mediated increase of M-MDSC and decrease of PMN-MDSC frequency has recently been described in the context of chronic CMV infection, which was linked to an IFN-mediated induction of IRF8 expression in myeloid precursor cells [23]. The expression of MHC-I and
PD-L1 were markedly elevated upon poly $(\mathrm{I}: \mathrm{C})_{\mathrm{c}}$ treatment, but greatly reduced in IFNAR-deficient mice. This is not surprising, as MHC-I and PD-L1 belong to the group of IFN-stimulated genes, which is in line with a recent report showing IFN as inducer of PD-L1 on MDSC [56]. However, the observed IFNAR1-dependent alterations in immune cell activation, which also included a profound $\mathrm{T}$ cell activation, are characteristic for the transition of a "cold" towards a "hot" tumor. Antigen presentation and T cell priming play a central role in anti-tumor immunity and IFN is required for efficient cross-presentation by DC. Immune escape mechanisms, such as downregulated MHC-I expression, are frequently used by tumors to evade immune responses. The expression of MHC-I molecules is a crucial event in engaging tumor-reactive $\mathrm{T}$ cells, and we confirmed upregulated MHC-I expression on tumors following poly $(\mathrm{I}: \mathrm{C})_{\mathrm{c}}$ treatment. We saw a strong therapy-induced decrease of TAM, which - similar to MDSC - mediated profound T cell inhibition in vitro. Furthermore, therapy decreased M2 polarization of TAM. However, in contrast to MDSC, the suppressive phenotype of TAM was not altered by poly $(\mathrm{I}: \mathrm{C})_{\mathrm{c}}$ therapy. Genes associated with antigen presentation were upregulated upon poly $(\mathrm{I}: \mathrm{C})_{\mathrm{c}}$ treatment, and there are several reports of immunotherapeutic strategies that induce antigen presentation by MDSC, including TLR agonists [40]. In our model, poly $(\mathrm{I}: \mathrm{C})_{\mathrm{c}}$ was used as MDA5-specific agonist and we cannot rule out potential TLR3 engagement; nevertheless, we did not observe cross-presentation of tumor-associated antigen by MDSC.

Low and chronic IFN signaling is observed in tumorbearing hosts and has been linked to support the immunosuppressive network [54]. Similar observations have been made for other chronic disease models, such as Western diet-induced atherosclerosis or viral infections, in which chronic inflammation is accompanied by a type I IFN signature $[57,58]$. In line with this, we compared the transcriptomic profiling of PDAC bulk tumors with normal pancreas tissue and confirmed an upregulated cellular response to IFN- $\beta$ (adj. $p<0.01$ ) (Additional file 1: Figure S3D).

There is evidence that IFN can also repolarize neutrophils and macrophages to an anti-tumor phenotype [20, 59], which is in agreement with observations made for MDSC in terms of TLR7/8- and TLR9-targeted therapies [24, 40]. Both, the TLR and MDA5 signaling cascades, lead to the activation of a shared IRF3/7 signaling pathway, with the induction of proinflammatory cytokines and type I IFN. RLH-signaling also induces proinflammatory cytokines via the NF- $\kappa B$ pathway consequentially upregulating CXCL10 and IL-6 levels. Interestingly, we observed reduced IL-6 levels in IFNAR1-deficient mice pointing towards a role for IFN signaling in regulating inflammation. IFNAR signaling has been shown to amplify early proinflammatory cytokine 
production during virus infection [60]; therefore, it is conceivable that IFN and cytokine signaling mutually act on anti-tumor immunity. We found that poly $(\mathrm{I}: \mathrm{C})_{\mathrm{c}}$ treatment reduced the suppressive capacity of MDSC populations in wild-type mice, but not in IFNAR1-deficient mice. Of note, steady-state suppressive capacity of MDSC was significantly less-pronounces in IFNAR1-deficient hosts; thus, it is tempting to speculate that early- and late-stage IFN signaling share a causal relationship in MDSC development and tumor control.

\section{Conclusions}

This study provides an in-depth analysis of MDSC in RLH-based immunotherapy using a state-of-the-art genetic model of pancreatic cancer. Our systematic approach and comprehensive analysis of MDSC provide an interface of cell-specific transcriptomic data analysis and cancer immunology. Our work supports a rationale for RLH-ligands as promising combination partners for other immunebased strategies, including chemo- or radiotherapy, checkpoint inhibition or CAR-T cells. Thus, combination therapies might benefit from the remodeling capacities of the RLH-based immunotherapy, to achieve greater clinical improvements.

\section{Supplementary information}

Supplementary information accompanies this paper at https://doi.org/10. 1186/s40425-019-0778-7.

Additional file 1: Figure S1. Gating strategy for the identification of MDSC populations. Figure S2. Poly $(I: C)_{c}$ reduces macrophage frequency and activates macrophages, CDC, B and NK cells. Figure S3. Poly(l:C)c triggers transcriptional reprogramming of MDSC. Figure S4. Significantly regulated genes in PMN- and M-MDSC upon poly $(\mathrm{l}: \mathrm{C})_{C}$ therapy.

\section{Abbreviations}

ATRA: all-trans retinoic acid; CAR: Chimeric antigen receptor;

CCR2: Chemokine (C-C motif) receptor 2; CDC: conventional dendritic cell;

CXCR2: Chemokine (C-X-C motif) receptor 2; FDA: Food and Drug

Administration; G-CSF: Granulocyte colony-stimulating factor; GM-

CSF: Granulocyte-macrophage colony-stimulating factor; IFN: Interferon; IFNAR1: IFN alpha and beta receptor 1; IRF: Interferon regulatory factor; MDA5: Melanoma differentiation-associated protein 5; MDSC: Myeloidderived suppressor cells; MHC: Major histocompatibility complex; MMDSC: Monocytic MDSC; OVA : Ovalbumin; PCA : Principle component analysis; PDAC: Pancreatic ductal adenocarcinoma; PD-L1: Programmed cell death ligand 1; PMN-MDSC: Polymorphonuclear MDSC; RIG-I: Retinoic acid inducible gene I; RLH: RIG-l-like helicases; TAM: Tumor associated macrophages; TAN: Tumor-associated neutrophils; TAP: Transporter associated with antigen processing; TGF: Transforming growth factor; TLR: Toll-like receptor; TME: Tumor microenvironment

\section{Acknowledgments}

We thank PD Dr. Michael Hristov (Institut für Prophylaxe und Epidemiologie der Kreislaufkrankheiten, Poliklinik, Klinikum der Universität München) for performing the FACSorting of MDSC, Dr. Meino Rohlfs (Kinderklinik und Kinderpoliklinik, Klinikum der Universität München) for his assistance with the next generation sequencing experiment.

\section{Authors' contributions}

Conceptualization MS and PD; Formal Analysis PM, SVK, MK and CCF: Investigation PM, SVK, CH, CAR, DB, JA and PD; Resources SK; Writing -
Original Draft PM, MS and PD; Writing - Review \& Editing all authors; Supervision LMK, SE, MS and PD; Funding Acquisition SK, SE, MS and PD. All authors read and approved the final manuscript.

\section{Funding}

This work was funded by the Deutsche Forschungsgemeinschaft (DFG), project numbers DU1522/1-1 and SFB 1123/2 B07 (to P.D.), 329628492 - SFB 1321 and SCHN664/6-1 (to M.S.), FR2938/7-1 (to C.C.F.), the international doctoral program "i-Target: Immunotargeting of cancer" funded by the Elite Network of Bavaria (to M.S., S.K., S.E.), and the Marie-Sklodowska-Curie "Training Network for the Immunotherapy of Cancer (IMMUTRAIN)" funded by the H2020 program of the European Union (to S.E., S.K. and M.S.), as well as the Mildred-Scheel-Doktorandenprogramm funded by the Deutsche Krebshilfe (S.V.K. and M.S.) and the Förderprogramm für Forschung und Lehre (FöFoLe) funded by the Ludwig-Maximilians-Universität München (S.V.K., M.S., P.D. and L.M.K..)

\section{Availability of data and materials}

The datasets generated and/or analyzed during the current study are available in the Gene Expression Omninus (GEO) repository with the accession number GSE126879, https://www.ncbi.nlm.nih.gov/geo/query/acc. cgi?acc=GSE126879; Until publication, enter token "mrcrekiwpnippsp" into the box to access data.

\section{Ethics approval and consent to participate}

This study does not include human material. Animal experiments were performed according to ethical guidelines and were approved by the local government, Regierung von Oberbayern, Munich, Germany (55.2-1-54-2532175-12)

\section{Consent for publication}

Not applicable.

\section{Competing interests}

Parts of this work have been performed for the doctoral theses of P.M. and S.V.K., at the Ludwig-Maximilians-Universität München.

\section{Author details}

${ }^{1}$ Center of Integrated Protein Science Munich (CIPSM) and Division of Clinical Pharmacology, Klinikum der Universität München, Lindwurmstrasse 2a, 80337 Munich, Germany. ${ }^{2}$ Department of Neurosurgery, University Hospital, LMU Munich, 81377 Munich, Germany. ${ }^{3}$ Institute for Informatics, Ludwig-Maximilians-Universität München, 80333 Munich, Germany. ${ }^{4}$ Institute of Innate Immunity, University of Bonn, Venusberg-Campus 1, 53127 Bonn, Germany.

Received: 1 April 2019 Accepted: 22 October 2019

Published online: 06 November 2019

\section{References}

1. Rahib L, Smith BD, Aizenberg R, Rosenzweig AB, Fleshman JM, Matrisian LM. Projecting cancer incidence and deaths to 2030: the unexpected burden of thyroid, liver, and pancreas cancers in the United States. Cancer Res. 2014; 74(11):2913-21.

2. Morrison AH, Byrne $\mathrm{KT}$, Vonderheide $\mathrm{RH}$. Immunotherapy and prevention of pancreatic cancer. Trends Cancer. 2018;4(6):418-28.

3. Guerra C, Collado M, Navas C, Schuhmacher AJ, Hernandez-Porras I, Canamero $\mathrm{M}$, et al. Pancreatitis-induced inflammation contributes to pancreatic cancer by inhibiting oncogene-induced senescence. Cancer Cell. 2011;19(6):728-39.

4. Steele CW, Kaur Gill NA, Jamieson NB, Carter CR. Targeting inflammation in pancreatic cancer: clinical translation. World J Gastrointestinal Oncol. 2016; 8(4):380-8.

5. Porembka MR, Mitchem JB, Belt BA, Hsieh CS, Lee HM, Herndon J, et al. Pancreatic adenocarcinoma induces bone marrow mobilization of myeloidderived suppressor cells which promote primary tumor growth. Cancer Immunol Immunother. 2012;61(9):1373-85.

6. Ino Y, Yamazaki-Itoh R, Shimada K, Iwasaki M, Kosuge T, Kanai Y, et al. Immune cell infiltration as an indicator of the immune microenvironment of pancreatic cancer. Br J Cancer. 2013;108(4):914-23. 
7. Sharma P, Allison JP. The future of immune checkpoint therapy. Science. 2015;348(6230):56-61.

8. Teng MW, Ngiow SF, Ribas A, Smyth MJ. Classifying cancers based on T-cell infiltration and PD-L1. Cancer Res. 2015;75(11):2139-45.

9. Clark CE, Hingorani SR, Mick R, Combs C, Tuveson DA, Vonderheide RH. Dynamics of the immune reaction to pancreatic cancer from inception to invasion. Cancer Res. 2007;67(19):9518-27.

10. Stromnes IM, Hulbert A, Pierce RH, Greenberg PD, Hingorani SR. T-cell localization, activation, and clonal expansion in human pancreatic ductal adenocarcinoma. Cancer Immunol Res. 2017;5(11):978-91.

11. Binnewies M, Roberts EW, Kersten K, Chan V, Fearon DF, Merad M, et al. Understanding the tumor immune microenvironment (TIME) for effective therapy. Nat Med. 2018;24(5):541-50.

12. Pylayeva-Gupta Y, Lee KE, Hajdu CH, Miller G, Bar-Sagi D. Oncogenic Krasinduced GM-CSF production promotes the development of pancreatic neoplasia. Cancer Cell. 2012;21 (6):836-47.

13. Bayne LJ, Beatty GL, Jhala N, Clark CE, Rhim AD, Stanger BZ, et al. Tumorderived granulocyte-macrophage colony-stimulating factor regulates myeloid inflammation and T cell immunity in pancreatic cancer. Cancer Cell. 2012;21(6):822-35

14. Gabrilovich DI. Myeloid-Derived Suppressor Cells. Cancer Immunol Res. 2017;5(1):3-8.

15. Bronte V, Brandau S, Chen SH, Colombo MP, Frey AB, Greten TF, et al. Recommendations for myeloid-derived suppressor cell nomenclature and characterization standards. Nat Commun. 2016;7:12150.

16. Lu C, Redd PS, Lee JR, Savage N, Liu K. The expression profiles and regulation of PD-L1 in tumor-induced myeloid-derived suppressor cells. Oncoimmunology. 2016;5(12):e1247135.

17. Khaled YS, Ammori BJ, Elkord E. Increased levels of granulocytic myeloidderived suppressor cells in peripheral blood and tumour tissue of pancreatic cancer patients. J Immunol Res. 2014;2014:879897.

18. Martinez FO, Sica A, Mantovani A, Locati M. Macrophage activation and polarization. Front Biosci. 2008;13:453-61.

19. Fridlender ZG, Sun J, Kim S, Kapoor V, Cheng G, Ling L, et al. Polarization of tumor-associated neutrophil phenotype by TGF-beta: "N1" versus "N2" TAN. Cancer Cell. 2009;16(3):183-94.

20. Andzinski L, Kasnitz N, Stahnke S, Wu C-F, Gereke M, von KöckritzBlickwede $\mathrm{M}$, et al. Type I IFNs induce anti-tumor polarization of tumor associated neutrophils in mice and human. Int J Cancer. 2016;138(8): 1982-93.

21. Anani W, Shurin MR. Targeting myeloid-derived suppressor cells in Cancer. Adv Exp Med Biol. 2017;1036:105-28.

22. Almand B, Clark Jl, Nikitina E, van Beynen J, English NR, Knight SC, et al. Increased production of immature myeloid cells in cancer patients: a mechanism of immunosuppression in cancer. J Immunol. 2001;166(1):678-89.

23. Dangi A, Zhang L, Zhang X, Luo X. Murine CMV induces type 1 IFN that impairs differentiation of MDSCs critical for transplantation tolerance. Blood Adv. 2018;2(6):669-80

24. Zoglmeier C, Bauer H, Norenberg D, Wedekind G, Bittner P, Sandholzer N, et al. CpG blocks immunosuppression by myeloid-derived suppressor cells in tumor-bearing mice. Clin Cancer Res. 2011;17(7):1765-75.

25. Kakizaki A, Fujimura T, Furudate S, Kambayashi Y, Yamauchi T, Yagita H, et al. Immunomodulatory effect of peritumorally administered interferon-beta on melanoma through tumor-associated macrophages. Oncoimmunology. 2015; 4(11):e1047584.

26. Duewell P, Steger A, Lohr H, Bourhis H, Hoelz H, Kirchleitner SV, et al. RIG-1like helicases induce immunogenic cell death of pancreatic cancer cells and sensitize tumors toward killing by CD8(+) T cells. Cell Death Differ. 2014; 21(12):1825-37.

27. Duewell P, Beller E, Kirchleitner SV, Adunka T, Bourhis H, Siveke J, et al. Targeted activation of melanoma differentiation-associated protein 5 (MDA5) for immunotherapy of pancreatic carcinoma. Oncoimmunology. 2015:4(10):e1029698.

28. Ellermeier J, Wei J, Duewell P, Hoves S, Stieg MR, Adunka T, et al. Therapeutic efficacy of bifunctional siRNA combining TGF-beta1 silencing with RIG-I activation in pancreatic cancer. Cancer Res. 2013; 73(6):1709-20

29. Poeck H, Besch R, Maihoefer C, Renn M, Tormo D, Morskaya SS, et al. 5'triphosphate-siRNA: turning gene silencing and rig-l activation against melanoma. Nat Med. 2008;14(11):1256-63.
30. Meng G, Xia M, Xu C, Yuan D, Schnurr M, Wei J. Multifunctional antitumor molecule 5'-triphosphate siRNA combining glutaminase silencing and RIG-I activation. Int J Cancer. 2014;134(8):1958-71.

31. Moore MW, Carbone FR, Bevan MJ. Introduction of soluble protein into the class I pathway of antigen processing and presentation. Cell. 1988; 54(6):777-85.

32. Bonfert T, Kirner E, Csaba G, Zimmer R, Friedel CC. ContextMap 2: fast and accurate context-based RNA-seq mapping. BMC Bioinformatics. 2015;16:122.

33. Li H, Durbin R. Fast and accurate long-read alignment with BurrowsWheeler transform. Bioinformatics (Oxford, England). 2010;26(5):589-95.

34. Liao Y, Smyth GK, Shi W. featureCounts: an efficient general purpose program for assigning sequence reads to genomic features. Bioinformatics (Oxford, England). 2014;30(7):923-30.

35. Love MI, Huber W, Anders S. Moderated estimation of fold change and dispersion for RNA-seq data with DESeq2. Genome Biol. 2014;15(12):550

36. Benjamini $Y$, Hochberg $Y$. Controlling the false discovery rate: a practical and powerful approach to multiple testing. J Roy Statist Soc. 1995;57(1):289-300.

37. Kluge M, Friedel CC. Watchdog - a workflow management system for the distributed analysis of large-scale experimental data. BMC Bioinformatics. 2018;19(1):97.

38. Subramanian A, Tamayo P, Mootha VK, Mukherjee S, Ebert BL, Gillette MA, et al. Gene set enrichment analysis: a knowledge-based approach for interpreting genome-wide expression profiles. Proc Natl Acad Sci U S A. 2005;102(43):15545-50.

39. Huang da W, Sherman BT, Lempicki RA. Systematic and integrative analysis of large gene lists using DAVID bioinformatics resources. Nat Protoc 2009; 4(1):44-57.

40. Spinetti T, Spagnuolo L, Mottas I, Secondini C, Treinies M, Ruegg C, et al. TLR7-based cancer immunotherapy decreases intratumoral myeloid-derived suppressor cells and blocks their immunosuppressive function. Oncoimmunology. 2016;5(11):e1230578.

41. Clawson GA, Matters GL, Xin P, McGovern C, Wafula E, dePamphilis C, et al. "Stealth dissemination" of macrophage-tumor cell fusions cultured from blood of patients with pancreatic ductal adenocarcinoma. PLoS One. 2017; 12(9):e0184451.

42. Seifert L, Werba G, Tiwari S, Giao Ly NN, Nguy S, Alothman S, et al. Radiation therapy induces macrophages to suppress T-cell responses against pancreatic tumors in mice. Gastroenterology 2016;150(7):1659-1672 e5.

43. Miyasato Y, Shiota T, Ohnishi K, Pan C, Yano H, Horlad H, et al. High density of CD204-positive macrophages predicts worse clinical prognosis in patients with breast cancer. Cancer Sci. 2017;108(8):1693-700.

44. Hingorani SR, Wang L, Multani AS, Combs C, Deramaudt TB, Hruban RH, et al. Trp53R172H and KrasG12D cooperate to promote chromosomal instability and widely metastatic pancreatic ductal adenocarcinoma in mice. Cancer Cell. 2005;7(5):469-83.

45. Lang S, Bruderek K, Kaspar C, Hoing B, Kanaan O, Dominas N, et al. Clinical relevance and suppressive capacity of human myeloid-derived suppressor cell subsets. Clin Cancer Res. 2018;24(19):4834-44.

46. Li J, Byrne KT, Yan F, Yamazoe T, Chen Z, Baslan T, et al. Tumor cell-intrinsic factors underlie heterogeneity of immune cell infiltration and response to immunotherapy. Immunity 2018;49(1):178-193 e7.

47. Bodogai M, Moritoh K, Lee-Chang C, Hollander CM, Sherman-Baust CA, Wersto RP, et al. Immunosuppressive and Prometastatic functions of myeloid-derived suppressive cells rely upon education from tumorassociated B cells. Cancer Res. 2015;75(17):3456-65.

48. Dolcetti L, Peranzoni E, Ugel S, Marigo I, Fernandez Gomez A, Mesa C, et al. Hierarchy of immunosuppressive strength among myeloid-derived suppressor cell subsets is determined by GM-CSF. Eur J Immunol. 2010; 40(1):22-35.

49. Veglia F, Perego M, Gabrilovich D. Myeloid-derived suppressor cells coming of age. Nat Immunol. 2018;19(2):108-19.

50. Condamine T, Gabrilovich DI. Molecular mechanisms regulating myeloidderived suppressor cell differentiation and function. Trends Immunol. 2011; 32(1):19-25.

51. Li W, Zhang X, Chen Y, Xie Y, Liu J, Feng Q, et al. G-CSF is a key modulator of MDSC and could be a potential therapeutic target in colitis-associated colorectal cancers. Protein Cell. 2016;7(2):130-40.

52. Ravindranathan S, Nguyen KG, Kurtz SL, Frazier HN, Smith SG, Koppolu BP, et al. Tumor-derived granulocyte colony-stimulating factor diminishes efficacy of breast tumor cell vaccines. Breast Cancer Res. 2018;20(1):126. 
53. Nywening TM, Belt BA, Cullinan DR, Panni RZ, Han BJ, Sanford DE, et al. Targeting both tumour-associated CXCR2(+) neutrophils and CCR2(+) macrophages disrupts myeloid recruitment and improves chemotherapeutic responses in pancreatic ductal adenocarcinoma. Gut. 2018;67(6):1112-23.

54. Snell LM, McGaha TL, Brooks DG. Type I interferon in chronic virus infection and cancer. Trends Immunol. 2017;38(8):542-57.

55. Bald T, Landsberg J, Lopez-Ramos D, Renn M, Glodde N, Jansen P, et al. Immune cell-poor melanomas benefit from PD-1 blockade after targeted type I IFN activation. Cancer Discovery. 2014;4(6):674-87.

56. Bazhin AV, von Ahn K, Fritz J, Werner J, Karakhanova S. Interferon-alpha upregulates the expression of PD-L1 molecules on immune cells through STAT3 and p38 signaling. Front Immunol. 2018;9:2129.

57. Christ A, Gunther P, Lauterbach MAR, Duewell P, Biswas D, Pelka K, et al. Western diet triggers NLRP3-dependent innate immune reprogramming. Cell. 2018;172(1-2):162-75 e14.

58. Norris BA, Uebelhoer LS, Nakaya HI, Price AA, Grakoui A, Pulendran B. Chronic but not acute virus infection induces sustained expansion of myeloid suppressor cell numbers that inhibit viral-specific T cell immunity. Immunity. 2013;38(2):309-21.

59. Sang Y, Miller LC, Blecha F. Macrophage polarization in virus-host interactions. J Clin Cellu Immunol. 2015;6(2).

60. Goritzka M, Durant LR, Pereira C, Salek-Ardakani S, Openshaw PJ, Johansson C. Alpha/beta interferon receptor signaling amplifies early proinflammatory cytokine production in the lung during respiratory syncytial virus infection. J Virol. 2014;88(11):6128-36.

\section{Publisher's Note}

Springer Nature remains neutral with regard to jurisdictional claims in published maps and institutional affiliations.

Ready to submit your research? Choose BMC and benefit from:

- fast, convenient online submission

- thorough peer review by experienced researchers in your field

- rapid publication on acceptance

- support for research data, including large and complex data types

- gold Open Access which fosters wider collaboration and increased citations

- maximum visibility for your research: over $100 \mathrm{M}$ website views per year

At $\mathrm{BMC}$, research is always in progress.

Learn more biomedcentral.com/submissions 